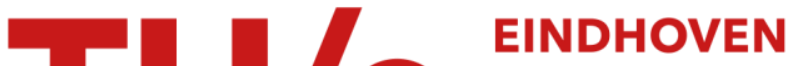 UNIVERSITY OF TECHNOLOGY
}

\section{Oxygen evolution and recombination kinetics inside sealed rechargeable, Ni-based batteries}

Citation for published version (APA):

Notten, P. H. L., Verbitskiy, E. A., Kruijt, W. S., \& Bergveld, H. J. (2005). Oxygen evolution and recombination kinetics inside sealed rechargeable, Ni-based batteries. Journal of the Electrochemical Society, 152(7), A1423A1433. https://doi.org/10.1149/1.1921849

DOI:

10.1149/1.1921849

Document status and date:

Published: 01/01/2005

Document Version:

Publisher's PDF, also known as Version of Record (includes final page, issue and volume numbers)

Please check the document version of this publication:

- A submitted manuscript is the version of the article upon submission and before peer-review. There can be important differences between the submitted version and the official published version of record. People interested in the research are advised to contact the author for the final version of the publication, or visit the $\mathrm{DOI}$ to the publisher's website.

- The final author version and the galley proof are versions of the publication after peer review.

- The final published version features the final layout of the paper including the volume, issue and page numbers.

Link to publication

\section{General rights}

Copyright and moral rights for the publications made accessible in the public portal are retained by the authors and/or other copyright owners and it is a condition of accessing publications that users recognise and abide by the legal requirements associated with these rights.

- Users may download and print one copy of any publication from the public portal for the purpose of private study or research.

- You may not further distribute the material or use it for any profit-making activity or commercial gain

- You may freely distribute the URL identifying the publication in the public portal.

If the publication is distributed under the terms of Article 25fa of the Dutch Copyright Act, indicated by the "Taverne" license above, please follow below link for the End User Agreement:

www.tue.nl/taverne

Take down policy

If you believe that this document breaches copyright please contact us at:

openaccess@tue.nl

providing details and we will investigate your claim. 


\title{
Oxygen Evolution and Recombination Kinetics Inside Sealed Rechargeable, Ni-Based Batteries
}

\author{
P. H. L. Notten, ${ }^{\text {a,b, } *, z}$ E. Verbitskiy, ${ }^{a}$ W. S. Kruijt, ${ }^{a}$ and H. J. Bergveld ${ }^{a}$ \\ ${ }^{a}$ Philips Research Laboratories, 5656 AA Eindhoven, The Netherlands \\ ${ }^{b}$ Eindhoven University of Technology, 5612 AZ Eindhoven, The Netherlands
}

\begin{abstract}
The oxygen evolution and recombination kinetics in Ni-based battery systems have been investigated under temperaturecontrolled, steady-state, overcharging conditions within a temperature range of $0-60^{\circ} \mathrm{C}$. Theoretical relationships for both reactions have been derived. The mathematical relationships have been confirmed by experiments on sealed rechargeable NiCd batteries. Under steady-state overcharging conditions, the Cd electrode potential was proven to be constant, thereby significantly reducing the complexity of the interpretation of the results. The oxygen evolution reaction was found to be a two-step process at the Ni electrode: two linear Tafel dependencies were found at low and high currents, separated by a transition region at intermediate currents. The oxygen recombination kinetics was found to be first-order in partial oxygen pressure, strongly suggesting that the recombination reaction is purely diffusion-controlled by oxygen, redissolved into the electrolyte, to the Cd electrode surface. For all reactions, activation energies have been determined. The results can directly be applied to aqueous battery models and give more insight into both the overcharging and self-discharge processes occurring in these Ni-based systems.

(C) 2005 The Electrochemical Society. [DOI: 10.1149/1.1921849] All rights reserved.
\end{abstract}

Manuscript submitted August 2, 2004; revised manuscript received January 7, 2005. Available electronically June 16,2005

The use of portable electronic equipment such as, for example, computers, telephones, shavers, and power tools, has been rapidly growing during the last few decades. Obviously, to power these portable devices, small rechargeable batteries are indispensable. In addition, the use of secondary batteries in the automotive sector is also growing sharply. Large batteries and battery packs are increasingly used to power (hybrid) electrical vehicles (EVs and HEVs).

Various sealed rechargeable battery types are presently available for energy storage. The three most frequently applied battery systems in these applications are the aqueous $\mathrm{NiCd}^{1}$ and nickel-metal hydride $(\mathrm{NiMH})^{2,3}$ systems and the nonaqueous Li-ion system, ${ }^{4}$ each of them having specific advantages and disadvantages. While operation of the more expensive Li-ion batteries requires quite a few electronic safety precautions, ${ }^{5} \mathrm{Ni}$-based systems can be operated in a relatively simple way, making the mature and robust $\mathrm{NiCd}$ and NiMH batteries economically attractive for a wide range of applications.

One of the most important requirements for aqueous battery systems is that they must be resistant to prolonged overcharging. It is well known that at the end of the charging process and during overcharging, a severe competition occurs between, on the one hand, the main electrochemical energy storage reactions and, on the other hand, the parasitic oxygen evolution and recombination reactions. ${ }^{1-3}$ The kinetics of these reactions determine the internal gas pressure, which will be established inside the batteries during (over)charging and ultimately determine at which rate these batteries can be charged. Evidently, to operate Ni-based batteries under a wide variety of charging conditions, the oxygen gas pressure must remain within reasonable limits. This puts some serious demands on the kinetics of the oxygen evolution and recombination reactions.

Nowadays, a lot of effort has been devoted to model rechargeable batteries, including both aqueous and nonaqueous systems. ${ }^{5-8}$ In recent work, it has been shown that the voltage characteristics, including the accompanying pressure and temperature behavior of both sealed rechargeable $\mathrm{NiCd}^{5,9,10}$ and $\mathrm{NiMH}^{11}$ batteries, can be successfully modeled. Using these models, it has been illustrated that this way of modeling is helpful to simulate not only these complex battery characteristics, but also the mutual electrical and thermal interaction between the battery or battery pack and the electronics used in the application. ${ }^{5,12}$ In order to introduce the appropriate processes and corresponding parameters into these models, more insight in the oxygen kinetics is required. The aim of the present paper is to investigate the kinetics of both the oxygen evo-

* Electrochemical Society Active Member.

${ }^{\mathrm{z}}$ E-mail: Peter.Notten@Philips.com lution and oxygen recombination reaction inside sealed Ni-based battery systems under practical battery operating conditions rather than to clarify the detailed mechanism of the oxygen recombination reactions.

As shown in this paper, the electrode potential of the individual electrodes plays an important role in the oxygen reaction kinetics. In contrast to the metal hydride $(\mathrm{MH})$ electrode, the cadmium electrode is based on a dissolution/precipitation mechanism, ultimately resulting in a two-phase, solid-state, redox system. ${ }^{13}$ This implies that the cadmium electrode potential, in contrast to the MH electrode potential, is independent of its state-of-charge (SOC) and can be considered as constant under certain conditions, thereby significantly simplifying the theoretical and experimental complexity for the oxygen kinetics. In this paper, we therefore concentrate on unraveling the oxygen evolution and recombination kinetics in $\mathrm{NiCd}$ batteries. The impact of these results on the corresponding kinetics in $\mathrm{NiMH}$ is discussed.

\section{Theoretical Considerations}

When NiCd batteries are charged $(c h)$, electrical energy is converted into chemical energy and the reverse process takes place during discharging $(d)$. The main electrochemical energy storage reactions can, in their most simplified form, be represented by

$$
\begin{gathered}
\mathrm{Ni}(\mathrm{OH})_{2}+\mathrm{OH}^{-} \underset{d}{\stackrel{c h}{\rightleftarrows}} \mathrm{NiOOH}+\mathrm{H}_{2} \mathrm{O}+\mathrm{e}^{-} \\
\mathrm{Cd}(\mathrm{OH})_{2}+2 \mathrm{e}^{-} \underset{d}{\stackrel{c h}{\rightleftarrows}} \mathrm{Cd}+2 \mathrm{OH}^{-}
\end{gathered}
$$

Since the Ni electrode is designed to be the capacity-determining electrode in NiCd batteries, ${ }^{10}$ it is generally accepted that an oxygen recombination cycle is initiated at the end of the charging process: $\mathrm{O}_{2}$ is evolved at the $\mathrm{Ni}$ electrode and will recombine at the $\mathrm{Cd}$ electrode. The overall oxygen evolution reaction at the $\mathrm{Ni}$ electrode can, in its most simplified form, be represented by

$$
4 \mathrm{OH}^{-} \underset{k_{c}}{\stackrel{k_{a}}{\rightleftarrows}} \mathrm{O}_{2}(l)+2 \mathrm{H}_{2} \mathrm{O}+4 \mathrm{e}^{-}
$$

where it is assumed that the produced oxygen dissolves into the liquid electrolyte $(l)$. A more detailed reaction sequence is treated in the Discussion. Equilibrium exists between oxygen dissolved in the electrolyte, $\mathrm{O}_{2}(l)$, and that present in the gas phase, $\mathrm{O}_{2}(g)$. This equilibrium can be represented by 


$$
\mathrm{O}_{2}(l) \underset{k_{2}}{\stackrel{k_{1}}{\rightleftarrows}} \mathrm{O}_{2}(g)
$$

where $k_{1}$ and $k_{2}$ are the respective rate constants. Because $\mathrm{Cd}(\mathrm{OH})_{2}$ is present in excess in the Cd electrode, ${ }^{10}$ reduction of $\mathrm{Cd}(\mathrm{OH})_{2}$ still continues, according to Reaction 2. As a result, the partial oxygen pressure within the cell starts to rise and electrochemical conversion of $\mathrm{O}_{2}$ will slowly be initiated at the $\mathrm{Cd}$ electrode, according to

$$
\mathrm{O}_{2}(l)+2 \mathrm{H}_{2} \mathrm{O}+4 e^{-} \underset{k_{a}}{\stackrel{k_{c}}{\rightleftarrows}} 4 \mathrm{OH}^{-}
$$

A general expression for the external current supplied to the battery $\left(I_{\mathrm{NiCd}}\right)$ can now be given

$$
I_{\mathrm{NiCd}}=I_{\mathrm{Ni}}+I_{\mathrm{O}_{2}}=I_{\mathrm{Cd}}+I_{\mathrm{rec}}
$$

where the partial currents flowing through the Ni electrode, which are composed of the main electrochemical reaction $\left(I_{\mathrm{Ni}}\right)$ and the oxygen evolution reaction $\left(I_{\mathrm{O}_{2}}\right)$, must of course equalize the partial currents flowing through the $\mathrm{Cd}$ electrode, which are composed of the Cd energy storage reaction $\left(I_{\mathrm{Cd}}\right)$ and the oxygen recombination reaction $\left(I_{\text {rec }}\right)$.

From Eq. 5 it is clear that water is required to facilitate the recombination reaction. The most likely recombination mechanism is that oxygen coming from the $\mathrm{Ni}$ electrode is transported via the gas phase toward the $\mathrm{Cd}$ electrode. Here, oxygen redissolves into the electrolyte, and transport toward the Cd-electrode/electrolyte interface takes place by means of diffusion where it is, subsequently, electrochemically converted. The presence of three-phase boundary regions is generally accepted to play a crucial role in the recombination reaction.

The interplay between the oxygen evolution and oxygen recombination kinetics ultimately determines the development of the partial oxygen pressure inside NiCd batteries. The gas law represents the relationship between the partial oxygen pressure $\left(p_{\mathrm{O}_{2}}\right)$, the battery temperature $(T)$, and the free gas volume $\left(V_{g}\right)$ inside the battery, according to

$$
p_{\mathrm{O}_{2}}=\frac{R T m_{\mathrm{O}_{2}}}{V_{g}}
$$

where $R$ is the gas constant and $m_{\mathrm{O}_{2}}$ is the molar amount of $\mathrm{O}_{2}$ in both the gas phase and dissolved in the electrolyte. Since the solubility of $\mathrm{O}_{2}$ in strong alkaline solutions is very low compared to that stored in the gas phase, ${ }^{14}$ the contribution of the electrolyte phase to $m_{\mathrm{O}_{2}}$ may be neglected. Using Faraday's law, $m_{\mathrm{O}_{2}}$ can simply be calculated from the amount of $\mathrm{O}_{2}$ produced at the Ni electrode $\left(I_{\mathrm{O}_{2}}\right)$ and the amount of $\mathrm{O}_{2}$ recombining at the Cd electrode $\left(I_{\text {rec }}\right)$

$$
\frac{d m_{\mathrm{O}_{2}}}{d t}=\frac{I_{\mathrm{O}_{2}}-I_{\mathrm{rec}}}{n F}
$$

where $n$, the number of electrons involved, is 4 according to Eq. 3 and 5 and $F$ is the Faraday constant. Combining Eq. 7 and 8 leads to the general expression for the pressure development inside $\mathrm{NiCd}$

$$
\frac{d p_{\mathrm{O}_{2}}}{d t}=\frac{R T}{n F V_{g}}\left(I_{\mathrm{O}_{2}}-I_{\mathrm{rec}}\right)
$$

A special case can now be considered when the supplied current to the battery is entirely used to drive the oxygen evolution and recombination cycle. In this case, a steady-state situation is reached in the overcharging regime, where

$$
\frac{d p_{\mathrm{O}_{2}}}{d t}=0
$$

and hence that

$$
I_{\mathrm{NiCd}}=I_{\mathrm{O}_{2}}=I_{\mathrm{rec}}
$$

Under these conditions, electrochemical conversion of $\mathrm{Ni}$ and $\mathrm{Cd}$ species no longer takes place. As pointed out below, this steady-state condition has a lot of favorable interpretational advantages.

Oxygen evolution.- Since oxygen evolution at a fully charged $\mathrm{Ni}$ electrode takes place at relatively positive potentials, the kinetic description of this reaction can be considerably simplified by considering only the anodic branch of the Butler-Volmer equation, ${ }^{10}$ according to

$$
I_{\mathrm{O}_{2}}=I_{\mathrm{O}_{2}}^{o} \exp \left\{\frac{\alpha_{\mathrm{O}_{2}} n F \eta_{\mathrm{O}_{2}}}{R T}\right\}
$$

where $I_{\mathrm{O}_{2}}$ represents the partial oxygen evolution current, $\alpha_{\mathrm{O}_{2}}$ is the charge-transfer coefficient, and the exchange current, $I_{\mathrm{O}_{2}}^{O}$, is given by

$$
I_{\mathrm{O}_{2}}^{o}=n F A_{\mathrm{Ni}} k_{a}^{\left(1-\alpha_{\mathrm{O}_{2}}\right)} k_{c}^{\alpha_{\mathrm{O}_{2}}} a_{\mathrm{O}_{2}(l)}^{\alpha_{\mathrm{O}_{2}} x_{\mathrm{O}_{2}}} a_{\mathrm{H}_{2} \mathrm{O}}^{\alpha_{\mathrm{O}_{2}} y_{\mathrm{O}_{2}}} a_{\mathrm{OH}^{-}}^{\left(1-\alpha_{\mathrm{O}_{2}}\right) z_{\mathrm{O}_{2}}}
$$

(see derivations given in Ref. 2 and 10). In Eq. 13, $A_{\mathrm{Ni}}$ represents the $\mathrm{Ni}$ electrode surface area at which oxygen evolution takes place, $k_{a}$ and $k_{c}$ represent the respective anodic and cathodic reaction rate constants, $a_{i}$ is the bulk activities of the various electroactive species involved, and $x, y, z$ are the corresponding reaction orders. The overpotential, $\eta_{\mathrm{O}_{2}}$, in Eq. 12 is defined as the difference between the $\mathrm{Ni}$ electrode potential $\left(E_{\mathrm{Ni}}\right)$ and the oxygen equilibrium potential $\left(E_{\mathrm{O}_{2}}^{\mathrm{eq}}\right)$

$$
\eta_{\mathrm{O}_{2}}=E_{\mathrm{Ni}}-E_{\mathrm{O}_{2}}^{\mathrm{eq}}
$$

where, according to the Nernst equation, $E_{\mathrm{O}_{2}}^{\mathrm{eq}}$ is dependent on the oxygen activity at the interface

$$
E_{\mathrm{O}_{2}}^{\mathrm{eq}}=E_{\mathrm{O}_{2}}^{o}+\frac{R T}{n F} \ln \left\{\frac{a_{\mathrm{O}_{2}(l)}}{a_{\mathrm{O}_{2}}^{\mathrm{ref}}}\right\}^{x_{\mathrm{O}_{2}}}
$$

in which $E_{\mathrm{O}_{2}}^{o}$ is the standard redox potential of the $\mathrm{O}_{2} / \mathrm{OH}^{-}$redox couple and $a_{\mathrm{O}_{2}}^{\text {ref }}$ is the oxygen activity in the reference state. Both $a_{\mathrm{OH}^{-}}$and $a_{\mathrm{H}_{2} \mathrm{O}}$ have been included in $E_{\mathrm{O}_{2} / \mathrm{OH}^{-}}^{o}$, as they are considered to be constant in the concentrated battery electrolyte $(>8 \mathrm{M})$.

Assuming that oxygen behaves like an ideal gas, Eq. 4 reveals that the activity of oxygen dissolved in the electrolyte relates to the partial oxygen pressure $p_{\mathrm{O}_{2}}$, according to

$$
a_{\mathrm{O}_{2}(l)}=\frac{k_{2}}{k_{1}} a_{\mathrm{O}_{2}(g)}=\frac{\gamma_{\mathrm{O}_{2}} k_{2}}{k_{1}} p_{\mathrm{O}_{2}}=\kappa_{\mathrm{O}_{2}} p_{\mathrm{O}_{2}}
$$

where $\gamma_{\mathrm{O}_{2}}$ denotes the fugacity constant and $\kappa_{\mathrm{O}_{2}}\left(=\gamma_{\mathrm{O}_{2}} k_{2} / k_{1}\right)$ the solubility constant. The low value for $\kappa_{\mathrm{O}_{2}}$ (5.1 $\times 10^{-7} \mathrm{~mol} / \mathrm{m}^{3} \mathrm{~Pa}$ ) is determined by the low oxygen solubility in the strong alkaline battery electrolyte. ${ }^{14}$ Considering a similar equation for $p_{\mathrm{O}_{2}}^{\text {ref }}$, i.e., $a_{\mathrm{O}_{2}}^{\text {ref }}=\kappa_{\mathrm{O}_{2}} p_{\mathrm{O}_{2}}^{\text {ref }}$, Eq. 15 transforms into

$$
E_{\mathrm{O}_{2}}^{\mathrm{eq}}=E_{\mathrm{O}_{2}}^{o}+\frac{R T}{n F} \ln \left\{\frac{p_{\mathrm{O}_{2}}}{p_{\mathrm{O}_{2}}^{\mathrm{ref}}}\right\}^{x_{\mathrm{O}_{2}}}
$$

in which $p_{\mathrm{O}_{2}}^{\text {ref }}$ refers to the standard conditions of 1 atmosphere $\left(\approx 10^{5} \mathrm{~Pa}\right)$ and $298 \mathrm{~K}$.

Replacing $\eta_{\mathrm{O}_{2}}$ in Eq. 12 by means of Eq. 14 and 17 and eliminating $a_{\mathrm{O}_{2}(l)}$ in Eq. 13 for $p_{\mathrm{O}_{2}}$ (Eq. 16) yields

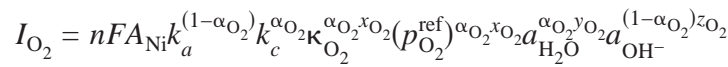

$$
\begin{aligned}
& \times p \exp \left[\frac{\alpha_{\mathrm{O}_{2}} n F}{R T}\left(E_{\mathrm{Ni}}-E_{\mathrm{O}_{2}}^{o}\right)\right]
\end{aligned}
$$

It should be noted that Eq. 18 reveals that the oxygen evolution 
kinetics is independent of the partial oxygen gas pressure, as expected from Eq. 3. Since the battery voltage is much more easily accessible than the individual electrode potentials in sealed batteries, $E_{\mathrm{NiCd}}\left(=E_{\mathrm{Ni}}-E_{\mathrm{Cd}}\right)$ is introduced in Eq. 18, which ultimately leads to

$$
I_{\mathrm{O}_{2}}=K_{\mathrm{O}_{2}} \exp \left[\frac{\alpha_{\mathrm{O}_{2}} n F}{R T}\left(E_{\mathrm{Cd}}-E_{\mathrm{O}_{2}}^{o}\right)\right] \exp \left[\frac{\alpha_{\mathrm{O}_{2}} n F}{R T} E_{\mathrm{NiCd}}\right]
$$

in which $\mathrm{K}_{\mathrm{O}_{2}}$ can be considered as a modified form of the exchange current (see Eq. 13)

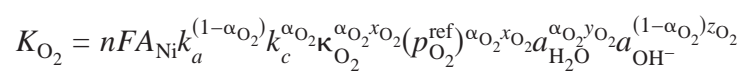

Considering the special condition of steady state when $d p_{\mathrm{O}_{2}} / d t$ $=0\left(\right.$ Eq. 10), the electrochemical reduction of $\mathrm{Cd}(\mathrm{OH})_{2}$ no longer takes place and $I_{\mathrm{NiCd}}=I_{\mathrm{O}_{2}}=I_{\text {rec }}$. Consequently, the overpotential at the $\mathrm{Cd}$ electrode is 0 and, as will be experimentally confirmed, $E_{\mathrm{Cd}}$ can be considered as constant for the Cd two-phase system. Performing the experiments under these steady-state conditions and plotting the semilogarithmic form of the supplied current vs. the battery voltage, according to

$$
\ln I_{\mathrm{NiCd}}=\ln I_{\mathrm{O}_{2}}=\ln K_{\mathrm{O}_{2}}+\left\{\frac{\alpha_{\mathrm{O}_{2}} n F}{R T}\left(E_{\mathrm{Cd}}-E_{\mathrm{O}_{2}}^{o}\right)\right\}+\frac{\alpha_{\mathrm{O}_{2}} n F}{R T} E_{\mathrm{NiCd}}
$$

yields essential kinetic information for the oxygen evolution reaction. It should, however, be noted that both $E_{\mathrm{Cd}}$ and $E_{\mathrm{O}_{2}}^{o}$ are temperature-dependent via the change in entropy by

$$
E_{i}^{o}(T)=E_{i}^{o}(298)+(T-298) \frac{\Delta S_{i}}{n_{i} F}
$$

where the value for the entropy change $\Delta S_{i}$ can be either positive or negative depending on the thermodynamics of the reaction species (i). ${ }^{10}$

Oxygen recombination.-For a purely kinetically controlled oxygen reduction reaction, for which no transport limitations have to be considered, the partial recombination current $\left(I_{\text {kin }}\right)$ can be expressed by the cathodic branch of the Butler-Volmer equation

$$
I_{\text {kin }}=I_{\text {rec }}^{o} \exp \left\{\frac{-\left(1-\alpha_{\text {rec }}\right) n F \eta_{\mathrm{rec}}}{R T}\right\}
$$

where $I_{\text {rec }}^{o}$, the exchange current for the recombination reaction, is given by

$$
I_{\mathrm{rec}}^{o}=n F A_{\mathrm{Cd}} k_{a}^{\left(1-\alpha_{\mathrm{rec}}\right)} k_{c}^{\alpha_{\mathrm{rec}}} a_{\mathrm{O}_{2}}^{\alpha_{\mathrm{rec}} x_{\mathrm{rec}}} a_{\mathrm{H}_{2} \mathrm{O}}^{\alpha_{\mathrm{rec}} y_{\mathrm{rec}}} a_{\mathrm{OH}^{-}}^{\left(1-\alpha_{\mathrm{rec}}\right) z_{\mathrm{rec}}}
$$

It should, however, be noted that $k_{a}$ and $k_{c}$ do not necessarily need to be the same as those for the oxygen evolution reaction in Eq. 13. Considering similar elimination steps to those used to derive Eq. 19, we obtain

$$
I_{\text {rec }}=K_{\text {rec }} P_{\mathrm{O}_{2}}^{x_{\text {rec }}} \exp \left\{\frac{-\left(1-\alpha_{\text {rec }}\right) n F}{R T}\left(E_{\mathrm{Cd}}-E_{\mathrm{O}_{2}}^{o}\right)\right\}
$$

where

$$
K_{\mathrm{rec}}=n F A_{\mathrm{Cd}} k_{a}^{\left(1-\alpha_{\mathrm{rec}}\right)} k_{c}^{\alpha_{\mathrm{rec}}} \kappa_{\mathrm{O}_{2}}^{\alpha_{\mathrm{rec}} x_{\mathrm{rec}}}\left(p_{\mathrm{O}_{2}}^{\mathrm{ref}}\right)^{-x_{\mathrm{rec}}\left(1-\alpha_{\mathrm{rec}}\right)} a_{\mathrm{H}_{2} \mathrm{O}}^{\alpha_{\mathrm{rec}} y_{\mathrm{rec}}} a_{\mathrm{OH}^{-}}^{z_{\mathrm{rec}}\left(1-\alpha_{\mathrm{rec}}\right)}
$$

is composed of the various constants, which are now specified for the recombination reaction at the $\mathrm{Cd}$ electrode. Plotting the logarithmic form of Eq. 25 gives

$$
\ln I_{\mathrm{rec}}=\ln K_{\mathrm{rec}}+\left\{\frac{-\left(1-\alpha_{\mathrm{rec}}\right) n F}{R T}\left(E_{\mathrm{Cd}}-E_{\mathrm{O}_{2}}^{o}\right)\right\}+x_{\mathrm{rec}} \ln p_{\mathrm{O}_{2}}
$$

Again, under steady-state conditions, $E_{\mathrm{Cd}}$ can be considered as constant and both $\mathrm{x}_{\text {rec }}$ and $K_{\text {rec }}$ can be deduced from the slope and intercept, respectively, of the expected linear dependence. In contrast to the oxygen evolution kinetics, the recombination kinetics is, according to Eq. 5, indeed dependent on the partial oxygen pressure.

Since the oxygen reduction reaction takes place at very high overpotentials, i.e., at very negative potentials with respect to $E_{\mathrm{O}_{2}}^{\text {eq }}$, it is reasonable to assume that transport of $\mathrm{O}_{2}$ toward the electrode interface might become a limiting factor. Assuming that a linear concentration gradient is established across the diffusion layer thickness, the recombination rate can be described by

$$
I_{\mathrm{dif}}=\frac{n F A_{\mathrm{Cd}} D_{\mathrm{O}_{2}}\left(\bar{a}_{\mathrm{O}_{2(l)}}-a_{\mathrm{O}_{2}(l)}\right)}{\gamma_{\mathrm{O}_{2}} d_{\mathrm{O}_{2}}}
$$

where $D_{\mathrm{O}_{2}}$ is the diffusion coefficient for $\mathrm{O}_{2}$ in the electrolyte, $\bar{a}_{\mathrm{O}_{2(l)}}$ is the activity of oxygen in the bulk of the electrolyte, $\gamma_{\mathrm{O}_{2}}$ is the activity coefficient for dissolved oxygen, and $d_{\mathrm{O}_{2}}$ is the average diffusion layer thickness, through which $\mathrm{O}_{2}$ must be transported to the interface. In the extreme case, when the recombination rate is completely dominated by mass transport, $a_{\mathrm{O}_{2}(l)}$ at the electrode surface equals zero and the diffusion-controlled recombination current $\left(I_{\text {dif }}\right)$ can be reduced to

$$
I_{\text {dif }}=\frac{n F A_{\mathrm{Cd}} D_{\mathrm{O}_{2}} \mathrm{~K}_{\mathrm{O}_{2}} p_{\mathrm{O}_{2}}}{\gamma_{\mathrm{O}_{2}} d_{\mathrm{O}_{2}}}
$$

in which the partial oxygen pressure (Eq. 16) is again introduced. From Eq. 29 it is clear that a linear dependence between the recombination current and $p_{\mathrm{O}_{2}}$ is to be expected under purely diffusioncontrolled conditions.

\section{Experimental}

All experiments have been performed with commercial AA-size $\mathrm{NiCd}$ batteries of the type 80AAS (Matsushita Battery Industries). It is well known that, due to the initiated oxygen recombination reaction, a lot of heat will be produced inside the batteries, leading to a significant temperature rise. ${ }^{10}$ In order to perform proper kinetic studies at constant temperatures, water jackets made of well-heat conducting, copper were tightly adjusted around the batteries. To further improve the heat exchange between the batteries and the water jackets, the batteries were lubricated with a heat-conducting resin (heat sink compound 340 from Dow Corning, Belgium) before attachment. The temperature was controlled by means of a thermostat (Neslab) within the temperature range of $0-60^{\circ} \mathrm{C}$ (accuracy is $0.5^{\circ} \mathrm{C}$ ). The temperature of the batteries was measured by means of Pt-100 thermocouples within an accuracy of $0.5^{\circ} \mathrm{C}$.

To measure the gas pressure build-up during the experiments, small holes with a diameter of $1 \mathrm{~mm}$ were drilled in the flat bottoms of the batteries. To reduce the risk of electrolyte loss, this was done just before the experiments were started. Subsequently, the batteries together with the water jackets were placed into holders to which pressure transducers (Transamerica Instruments type no. 4702-10) were attached. Double O-ring constructions ensured gas-tight sealing between the batteries and transducers. The pressure was measured within an accuracy of 0.01 bar. In order not to disturb the battery behavior too much, the dead volume of the pressure transducer, including the supply tube, was kept as small as possible and was calibrated to be $1.17 \mathrm{~mL}$. This is less than the battery void volume, which was analyzed to be $1.8 \mathrm{~mL}$. Separate electrical contacts were used for current flow and voltage measurements.

Before starting the kinetic measurements all batteries were activated for at least 20 cycles under thermostatic conditions $\left(20^{\circ} \mathrm{C}\right)$ until constant charge/discharge behavior was attained. The condi- 
tions of such an activation cycle consisted of a 3-h charging period, using a $400-\mathrm{mA}$ current (0.5 C-rate) followed by an open-circuit period of $60 \mathrm{~min}$. Subsequently, the batteries were discharged with $400 \mathrm{~mA}$ until the cutoff voltage of $0.9 \mathrm{~V}$ was reached. After a resting period of $15 \mathrm{~min}$, the batteries were additionally deepdischarged, using a lower current of $80 \mathrm{~mA}(0.1 \mathrm{C})$, again until the same cutoff voltage was reached. The activation cycle was completed by a resting period of $15 \mathrm{~min}$.

The kinetics of the oxygen evolution and recombination reactions was investigated during continuously overcharging by stepwise changing the overcharging current. Fully discharged batteries were therefore initially charged under moderate current $(80 \mathrm{~mA})$ conditions for $20 \mathrm{~h}$ (200\% depth-of-charge) to ensure a steady-state situation in the overcharge region to be attained, as could be recognized on the constant values of the three measured parameters $(V, P$, and $T)$. After this period the current was lowered stepwise down to $5 \mathrm{~mA}$. The actual kinetic measurement was performed by increasing the current stepwise up to $2 \mathrm{~A}$. The stabilization time needed to attain a new steady state was obviously dependent on the applied current, and the overcharging period therefore ranged between 150 and $400 \mathrm{~min}$ for the high and low current region, respectively. This procedure was repeated at every temperature. To get the batteries used to a new ambient temperature, they were reactivated for three cycles before the kinetic measurements were performed. The reactivation cycling regime was the same as that used for the activation cycles described above. Flexible, in-house-designed, automatic cycling equipment was used to perform both the cycling experiments and the custom-type overcharging experiments. $V, P$, and $T$ values were continuously recorded.

Impedance measurements were performed with conventional equipment (Autolab from Ecochemie) under galvanostatic control during continuous overcharging with a constant dc-current $\left(I_{\mathrm{dc}}\right)$ in the range of $80<I_{\mathrm{dc}}<1120 \mathrm{~mA}$ and using an alternating current of $5 \mathrm{~mA}$. The investigated frequency range was from $10^{-1}$ to $10^{4} \mathrm{~Hz}$.

The equilibrium potential measurements of the $\mathrm{Ni}$ and $\mathrm{Cd}$ electrodes were performed under the same mechanical conditions as those in sealed batteries. After the batteries were completely activated and, subsequently, fully discharged, the caps accommodating the vents were removed and extra electrolyte with exactly the same composition as that used in the commercial batteries was added. ${ }^{15}$ An $\mathrm{Hg} / \mathrm{HgO}$ reference electrode was closely positioned above the winded electrode package. Also in this experimental setup, the battery was thermostated using the copper water jacket. The temperature was controlled at $20^{\circ} \mathrm{C}$. The fully discharged batteries were charged stepwise for $2.5 \mathrm{~min}$ with $0.5 \mathrm{C}(400 \mathrm{~mA})$. After current interruption, the electrodes were allowed to relax to their equilibrium potential for $5 \mathrm{~h}$ before the next charging step was initiated. To prevent the uncertainty of the state-of-charge (SOC) at higher values of SOC, resulting from the competition with the oxygen evolution reaction at the Ni electrode, a SOC value of $75 \%$ was taken as maximum, after which the current was reversed. However, some $E_{\mathrm{Cd}}^{\mathrm{eq}}$ measurements were also performed after current interruption in the overcharging region where the SOC of the Ni electrode is poorly defined. Both the $\mathrm{Ni}$ electrode $\left(E_{\mathrm{Ni}}\right)$ and $\mathrm{Cd}$ electrode potential $\left(E_{\mathrm{Cd}}\right)$ were monitored against the reference electrode. To check these measurements, the battery voltage $\left(E_{\mathrm{NiCd}}\right)$ was also inspected and was found to be in perfect agreement with the individual electrode potentials in all cases, i.e., $E_{\mathrm{NiCd}^{-}}\left(E_{\mathrm{Ni}^{-}} E_{\mathrm{Cd}}\right)<2 \mathrm{mV}$.

\section{Results}

Several activation cycles measured at $20^{\circ} \mathrm{C}$ are shown in Fig. 1. The first charging cycle [curve (a)] reveals that charging occurs at rather high voltages, especially in the region where the competition with the oxygen evolution and recombination reactions occurs. After $180 \mathrm{~min}$, the charging current was interrupted for $1 \mathrm{~h}$, which was followed by discharging the battery. The overcharging behavior changed drastically during the following charging procedures as

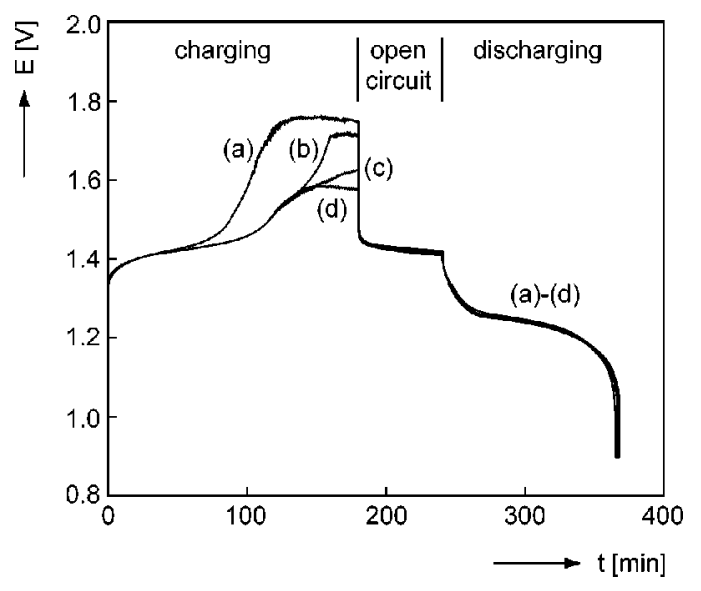

Figure 1. Example of activation cycles of an 80AAS NiCd battery during charging $(400 \mathrm{~mA})$, open-circuit, and discharging $(400 \mathrm{~mA})$ at $20^{\circ} \mathrm{C}$. Cycle 1 (a), cycle 2 (b), cycle 3 (c), and cycle 20 (d), after which the characteristics do not change anymore.

curves (b) and (c) show for the second and third charging cycle, respectively. After approximately 20 cycles [curve (d)], the voltage curves had stabilized and did not change anymore. The voltage dependence during both the open-circuit and discharging period is not very activation-dependent, indicating that activation is mainly related to the oxygen recombination cycle. In line with this observation, the discharge capacities are more or less the same for all cycles. It should be emphasized that the appearance of the voltage curves shown in Fig. 1 may deviate from those normally reported, such as the characteristic $-d V / d t$ behavior in the overcharge region. ${ }^{10}$ This is due to the special temperature-controlled conditions adopted in the present experiments, which are rather uncommon in battery research.

After the activation period was completed, the kinetic investigations were started. Part of the overcharging procedure is shown in Fig. 2. At $t=0$ (arbitrary value), the charging current was increased from 1.12 to $1.28 \mathrm{~A}$. The voltage increases rather abruptly and relaxes toward a new steady-state value within about $40 \mathrm{~min}$, while the pressure, on the other hand, slowly increases toward the new steady state. The relaxation times of the voltage and pressure curves are clearly coupled to one another. After stabilization, the current

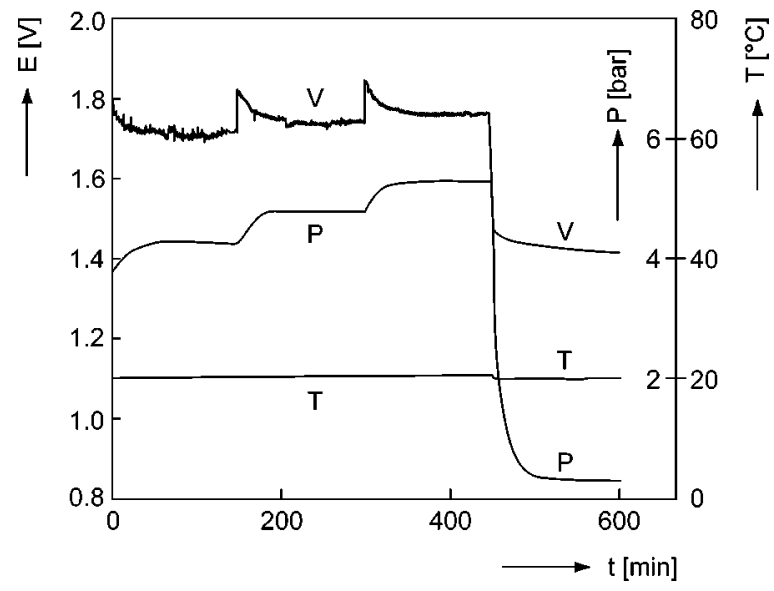

Figure 2. Typical example of part of the voltage $(V)$, pressure $(P)$, and temperature $(T)$ development during continuous overcharging at $20^{\circ} \mathrm{C}$. This part refers to the high-current region, where $I$ is increased stepwise from 1.12 to $1.28 \mathrm{~A}$ at $t=0$ via $1.44 \mathrm{~A}(t=150 \mathrm{~min})$ to $1.60 \mathrm{~A}(t=300 \mathrm{~min})$. After $450 \mathrm{~min}$, the current is switched off and the battery is allowed to relax to the equilibrium state under open-circuit conditions. 


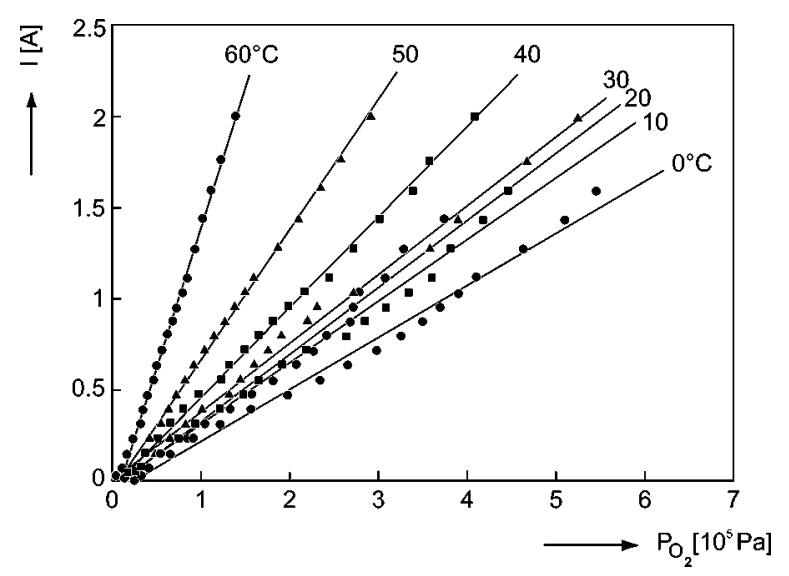

Figure 3. Overcharging current as a function of the established steady-state partial oxygen pressure inside the $\mathrm{NiCd}$ battery at various temperaturecontrolled conditions.

was further increased in two steps via $1.44 \mathrm{~A}$ at $150 \mathrm{~min}$ up to $1.60 \mathrm{~A}$ after $300 \mathrm{~min}$ (see Fig. 2). After the final steady-state situation was accomplished at the highest current, the current was switched off and both the voltage and pressure relaxed to their low equilibrium state. The temperature was fixed at $20^{\circ} \mathrm{C}$ throughout the experiment in this example, as Fig. 2 reveals.

The dependence of the established steady-state oxygen pressure on the applied overcharging current is shown in Fig. 3. Although some spread in the results is found, especially at low temperatures, very likely due to the severe development of oxygen bubbles at the $\mathrm{Ni}$ electrode, it can be seen that straight lines passing through the origin are obtained at all temperatures. As expected, the partial oxygen pressures are significantly reduced at higher temperatures.

The influence of the battery SOC on the electrode potentials of both the $\mathrm{Ni}$ and $\mathrm{Cd}$ electrode inside an opened NiCd battery is revealed in Fig. 4. Curves (a) and (b) refer to the open-circuit voltage $(\mathrm{OCV})$ dependencies of the Ni electrode during charging and discharging, respectively. The potentials were measured against an $\mathrm{Hg} / \mathrm{HgO}$ reference electrode. A large hysteresis was found between charging and discharging, which amounts to about $100 \mathrm{mV}$. In contrast to the Ni electrode, the open-circuit potential of the Cd elec-

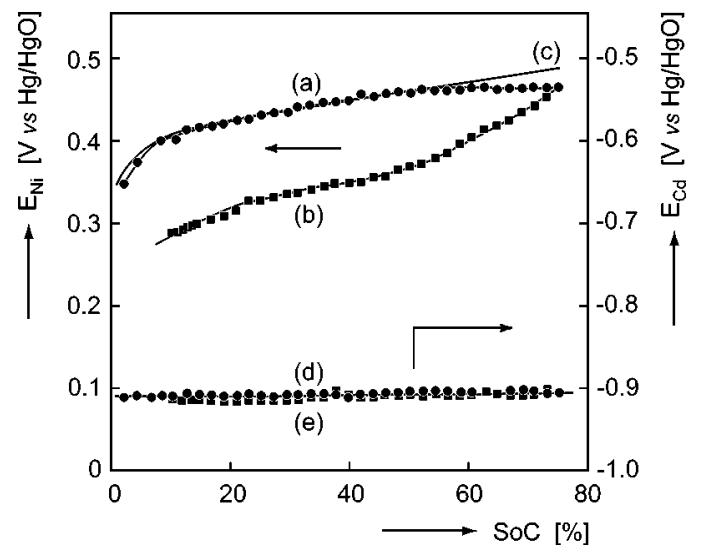

Figure 4. Ni electrode [curves (a) and (b)] and Cd electrode [curves (d) and (e)] open-circuit potential measured in an opened battery against an $\mathrm{Hg} / \mathrm{HgO}$ reference electrode at $20^{\circ} \mathrm{C}$ during intermittent charging [curves (a) and (d)] and discharging [curves (b) and (e)] with $400 \mathrm{~mA}$. Current-on period is $2.5 \mathrm{~min}$ and current-off period took $300 \mathrm{~min}$ before each potential measurement. Curve (c) represents the theoretically expected curve for the Ni electrode based on the Nernst equation, considering the attraction or repulsion energies to be negligible. ${ }^{10}$

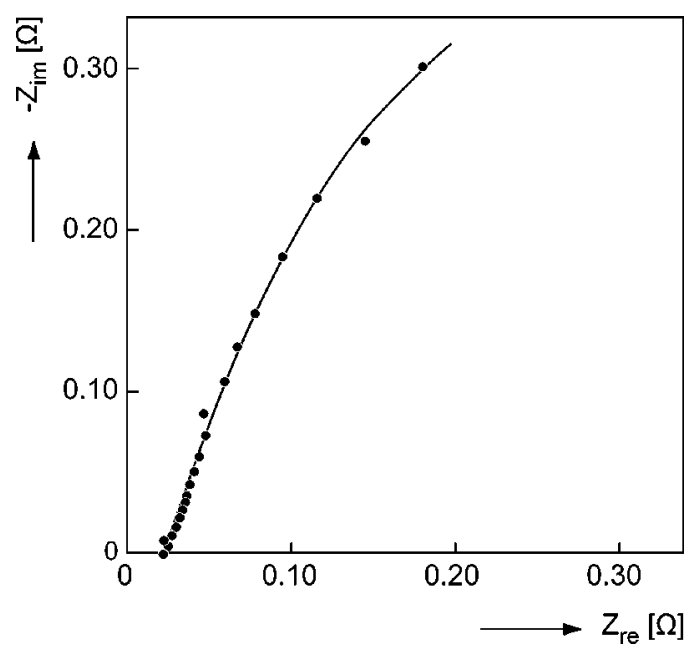

Figure 5. High-frequency region of a typical impedance measurement performed during continuously overcharging $(160 \mathrm{~mA})$ a NiCd battery thermostated at $20^{\circ} \mathrm{C}$. In this example, a steady-state battery voltage of $1.477 \mathrm{~V}$ was established.

trode does not show any dependence on the SOC within an accuracy of $2 \mathrm{mV}$. No sign of any hysteresis between the charging [curve (d)] and discharging OCV [curve (e)] was found in this case. The differences between measured $\mathrm{OCV}$ values for the $\mathrm{Ni}$ and $\mathrm{Cd}$ electrode are in perfect agreement (within $2 \mathrm{mV}$ ) with the measured battery voltage at all SOC values, as expected. Similar measurements have been performed in the overcharging region. Since the SOC of the Ni electrode is rather unreliable in this region due to the parasitic oxygen reaction, the $x$ axis of Fig. 4 becomes highly unreliable. However, the Cd electrode potential was found to remain at the same constant value, as indicated in Fig. 4, curves (d) and (e). This is indeed to be expected from the fact that both solid $\mathrm{Cd}$ and $\mathrm{Cd}(\mathrm{OH})_{2}$ species are still present in the $\mathrm{Cd}$ electrode as the capacity of this electrode is much larger than that of the capacity-determining $\mathrm{Ni}$ electrode.

In order to correct the measured battery voltage for the ohmic losses occurring under current flowing conditions, the sealed batteries were subjected to impedance measurements under steady-state overcharging conditions at various currents at $20^{\circ} \mathrm{C}$. A typical example of such an impedance measurement, using an overcharging current of $160 \mathrm{~mA}$, is shown in Fig. 5. Only the most informative part of the impedance spectrum at high frequencies is plotted. The intercept with the $x$ axis reveals the real part of the impedance, corresponding to an ohmic resistance of $23 \mathrm{~m} \Omega$. This value was found to be independent of the applied overcharging current within $\pm 0.5 \mathrm{~m} \Omega$ and is in agreement with what is usually accepted as ohmic resistance for this type of aqueous battery system. ${ }^{1,10}$ Considering the temperature dependency of the ionic conductivity $[\lambda(T)]$ of strong alkaline electrolytes,${ }^{14}$ the ohmic resistances at different temperatures $[R(T)]$ can be calculated, according to

$$
R(T)=\frac{R(293) \lambda(293)}{\lambda(T)}
$$

The as-calculated values are used for the Ohmic loss corrections at the other temperatures.

An example of a corrected current-voltage curve obtained with a sealed rechargeable battery under steady-state overcharging conditions at $0^{\circ} \mathrm{C}$ is shown in Fig. 6. Two separate regions can clearly be distinguished. These two regions become even more pronounced when the current is plotted on a logarithmic scale in Fig. 7. It is evident that at both low and high currents, the kinetics obeys simple Tafel relationships, which are represented by the straight lines of curves (a) and (b), respectively. In the intermediate current range, 


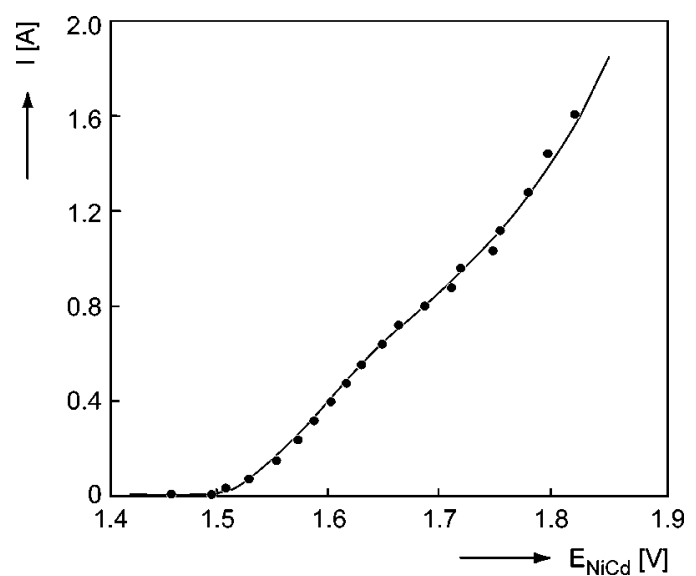

Figure 6. Current-voltage relationship measured during continuously overcharging a $\mathrm{NiCd}$ battery thermostated at $0^{\circ} \mathrm{C}$. The battery voltage has been corrected for the ohmic voltage drop. The overcharging current was increased stepwise (see Fig. 2).

a transfer from one Tafel region to another is found. Figure 8 shows the results at various temperatures. As expected from improved kinetics, the curves are shifted toward lower voltages at higher temperatures.

\section{Discussion}

The chemical and physical processes visualizing the oxygen evolution and recombination process inside $\mathrm{NiCd}$ batteries are schematically depicted in Fig. 9. The oxygen formed at the Ni electrode dissolves into the electrolyte $\left[\mathrm{O}_{2}\right]$ and will, subsequently, be transported to the gas phase $\left[\mathrm{O}_{2}\right]$. Since the oxygen solubility in alkaline electrolyte is relatively poor, ${ }^{14}$ transportation via the gas phase by means of gas bubbles will be the most dominant transportation mechanism. According to Eq. 5, the availability of water is essential for the oxygen recombination to occur. Redissolution of $\mathrm{O}_{2}$ into the electrolyte and diffusion toward the Cd-electrode/electrolyte interface is therefore an essential step. The availability of three-phase boundary regions seems to be crucial in this respect and semiwetted electrodes are therefore generally thought to be very favorable for a high recombination rate, as is schematically indicated in Fig. 9.

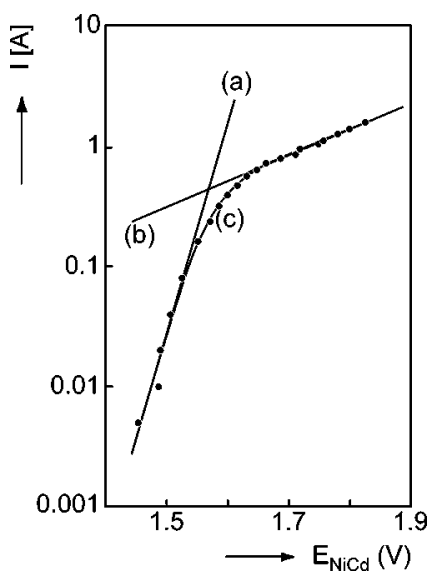

Figure 7. Same current-voltage relationship as shown in Fig. 6, now plotted on a semilogarithmic scale (filled circles). The characteristic low-current and high-current Tafel regions are represented by curves (a) and (b), respectively. Using the parameter values of these two Tafel regions, an overall currentvoltage dependence [curve (c)] can be calculated, according to Eq. 44-46 and Eq. 47.

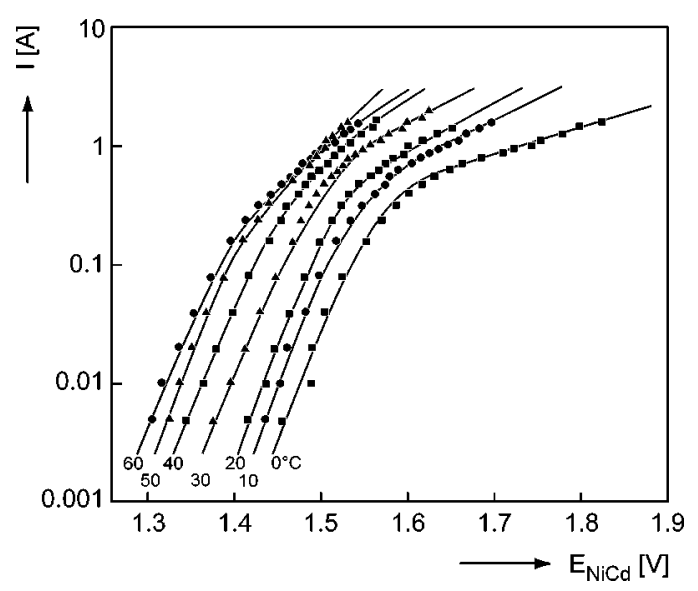

Figure 8. Current-voltage relationships measured at various controlled temperatures during continuous overcharging.

The present experimental results reveal that fully activated $\mathrm{NiCd}$ batteries (Fig. 1) can be overcharged to a large extent under temperature-controlled conditions. These conditions are required in order to properly investigate the kinetic properties of both the oxygen evolution and recombination reactions.

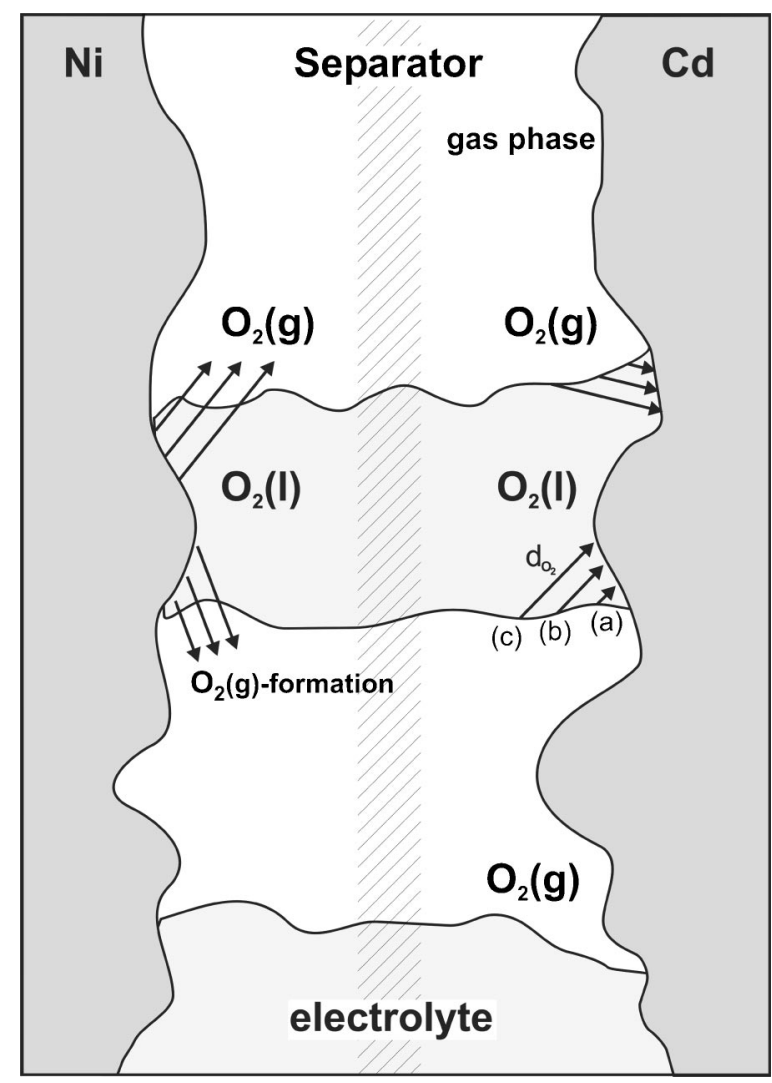

Figure 9. Schematic representation of the oxygen recombination cycle. The $\mathrm{Ni}$ and $\mathrm{Cd}$ electrodes are separated by a separator, which is immersed in the strong alkaline electrolyte. Oxygen formation is initiated at the Ni electrode/ electrolyte interface. Small gas bubbles are formed and the gas will be transported to the gas phase. Recombination starts by redissolution of oxygen in the electrolyte and will subsequently be reduced at the Cd-electrode/ electrolyte interface. The recombination rate is strongly dependent on the diffusion layer thickness, through which oxygen has to be transported and is most favorable at the three-phase boundaries, as is schematically indicated by arrows (a)-(c). 


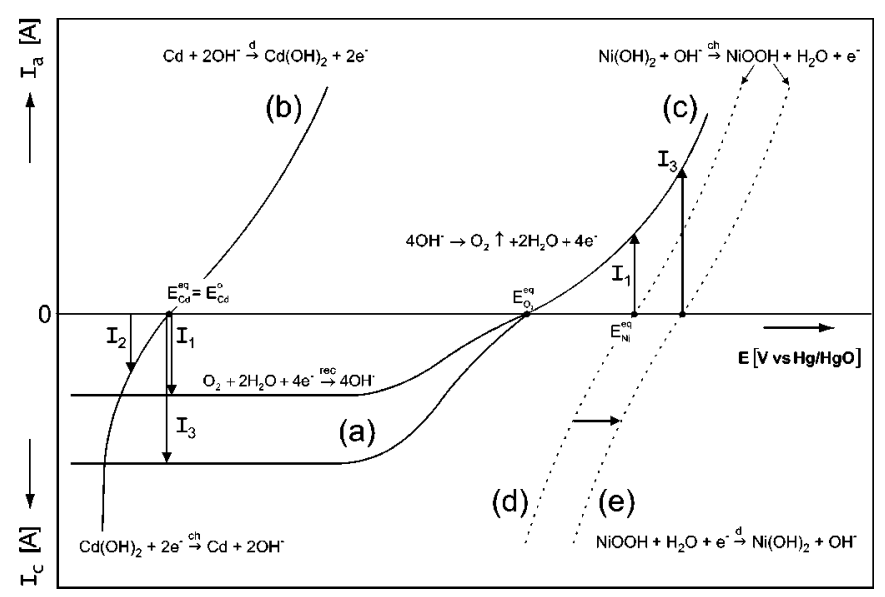

Figure 10. Electrochemical representation of the oxygen recombination process in a NiCd battery. The diffusion-controlled oxygen recombination process at the $\mathrm{Cd}$ electrode under steady-state overcharging conditions takes place at negative potentials with respect to the oxygen standard redox potential $\left(E_{\mathrm{O}_{2}}^{\text {eq }}\right)$ and is represented by the potential-independent current-voltage curves (a). Oxygen recombination takes place at the open-circuit potential of Cd electrode [curve (b)]. Under these steady-state conditions, the rate of oxygen recombination is equal to the rate of oxygen evolution [curve (c)], taking place at the open-circuit potential of the Ni electrode $\left[E_{\mathrm{Ni}}^{\mathrm{eq}}\right.$ on dashed curves $(\mathrm{d})]$ and is represented by $I_{1}$. Instantaneously increasing the overcharging current by an amount $I_{2}$ to $I_{3}\left(I_{3}=I_{1}+I_{2}\right)$ immediately induces the potential at the $\mathrm{Cd}$ electrode to decrease and that of the $\mathrm{Ni}$ electrode to increase. As a result, the battery voltage increases simultaneously (see Fig. 2). After relaxation toward the new steady-state situation, both oxygen evolution at the $\mathrm{Ni}$ electrode [curve (e)] and oxygen recombination curve (a) at the Cd electrode take place again at $E_{\mathrm{Ni}}^{\mathrm{eq}}$ and $E_{\mathrm{Cd}}^{\mathrm{eq}}$, respectively.

Figure 2 indicates that by changing the overcharge current, a new steady-state condition is attained within approximately $40 \mathrm{~min}$. Characteristic of this steady-state condition is that both the battery voltage and partial oxygen pressure have become constant. Consequently, according to Eq. 9 and 10, the rate of oxygen evolution is equal to that of oxygen recombination and the rates of the main electrochemical storage reactions, $I_{\mathrm{Ni}}$ and $I_{\mathrm{Cd}}$, are diminished to zero. This implies that Eq. 11 applies. For convenience, we first discuss the relevant consequences for the oxygen recombination kinetics and after that consider the oxygen evolution kinetics under these conditions.

Oxygen recombination.- Plotting the supplied battery current as a function of the steady-state partial oxygen pressure clearly shows that the recombination reaction is linearly dependent on $p_{\mathrm{O}_{2}}$ at all temperatures (Fig. 3). Assuming that the recombination reaction is purely kinetically controlled, it is evident that $x_{\text {rec }}$ in Eq. 25 must equal 1 . Since for a purely diffusion-controlled recombination a similar dependency applies (see Eq. 29) and it can theoretically be shown that this also holds for a combined, first-order, kinetic/ diffusion-controlled, reaction, it is impossible to conclude from this linear dependency what the rate-determining step for oxygen reduction at the $\mathrm{Cd}$ electrode is. However, considering that the $\mathrm{Cd}$ electrode potential $\left[E_{\mathrm{Cd}}=-0.808 \mathrm{~V} v s\right.$. a standard hydrogen electrode $\left.(\mathrm{SHE})^{10}\right]$, at which the oxygen reduction reaction takes place, is more than $1.2 \mathrm{~V}$ negative with respect to the equilibrium potential of the oxygen redox couple $\left(E_{\mathrm{O}_{2}}^{\mathrm{eq}}=+0.401 \mathrm{~V} v \mathrm{~s}\right.$. SHE at $\left.1 \mathrm{bar}^{10}\right)$, it is more than likely that oxygen reduction will be fully transportcontrolled. This is also the mechanism we adopted in our earlier battery modeling work. $5,9-12$

The diffusion-controlled, potential-independent recombination current at the $\mathrm{Cd}$ electrode is schematically represented by curves (a) in Fig. 10. In addition, the electrochemical charge-transfer processes of the $\mathrm{Cd}$ and $\mathrm{Ni}$ electrode are indicated by curves (b) and

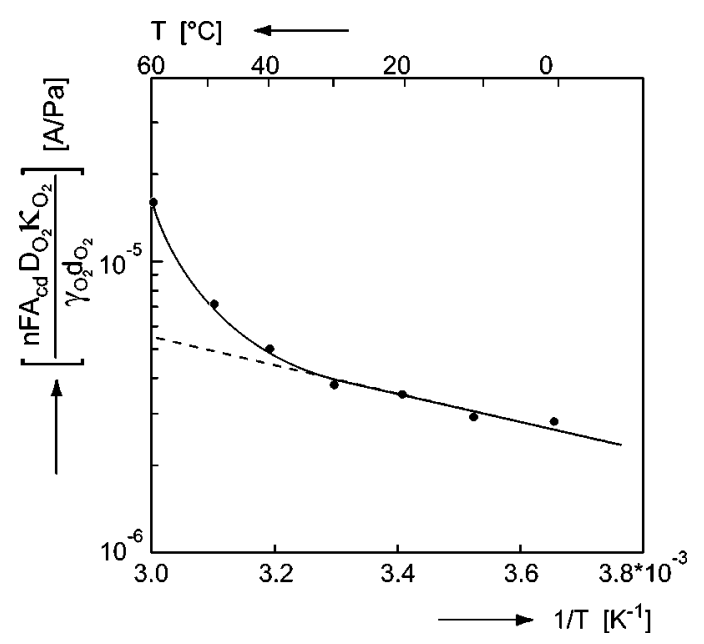

Figure 11. Calculated slope, as obtained from the current-pressure curves shown in Fig. 3 (see also corresponding Eq. 29), as a function of the reciprocal temperature.

(d),(e), respectively. As pointed out above, no current is consumed by both the $\mathrm{Ni}$ and $\mathrm{Cd}$ reaction under steady-state conditions and, consequently, oxygen evolution and recombination take place at $E_{\mathrm{Ni}}^{\mathrm{eq}}$ and $E_{\mathrm{Cd}}^{\mathrm{eq}}$, respectively. Under these conditions, the oxygen evolution rate at the Ni electrode, schematically indicated by $I_{1}$ in curve (c), equals the recombination rate at the Cd electrode $\left[I_{1}\right.$ in curve (a)]. The meaning of $I_{2}$ and $I_{3}$ is relevant for the non-steady-state conditions, as discussed later.

According to Eq. 29, information about the diffusion process can be obtained from the slopes of the lines found in Fig. 3. This equation shows that most of the factors influencing the recombination kinetics can be considered as constants, including $A_{\mathrm{Cd}}, D_{\mathrm{O}_{2}}, \kappa_{\mathrm{O}_{2}}$, and $\gamma_{\mathrm{O}_{2}}$. More difficult to access is the diffusion layer thickness, $d_{\mathrm{O}_{2}}$. It is clear from Fig. 9 that not only $A_{\mathrm{Ni}}$ but also $A_{\mathrm{Cd}}$ refers to the wetted part of the $\mathrm{Ni}$ and $\mathrm{Cd}$ electrode, respectively. Evidently, redissolution and transportation toward the electrode interface will occur fast near the solid-electrolyte-gas three-phase edges where the diffusion layer thickness is extremely small [see position (a) in Fig. 9]. The diffusion layer thickness increases quickly farther away from these three-phase edges, as is indicated by positions (b) and (c). Conclusively, there is a continuum in values for $d_{\mathrm{O}_{2}}$. In order to deal with such a continuum, $d_{\mathrm{O}_{2}}$ is considered to be an average diffusion layer thickness in the present work.

The as-obtained slopes from the $I$ vs. $p_{\mathrm{O}_{2}}$ relationship (Fig. 3) have been plotted according to an Arrhenius relationship in Fig. 11. A linear dependence is found at temperatures up to $40^{\circ} \mathrm{C}$. It has been shown by Davis et al. ${ }^{16}$ that the solubility of oxygen in the strong alkaline solutions used in rechargeable batteries is independent of the temperature within a temperature range of $0-60^{\circ} \mathrm{C}$ and hence that $\mathrm{K}_{\mathrm{O}_{2}}$ remains essentially constant. Assuming that both $A_{\mathrm{Cd}}$ and $d_{\mathrm{O}_{2}}$ are also temperature-independent, the observed Arrhenius behavior can be attributed to the temperature dependency of $D_{\mathrm{O}_{2}}$. Such dependence can be expressed by

$$
D_{\mathrm{O}_{2}}=D_{\mathrm{O}_{2}}^{o} \exp \left(\frac{-E_{\mathrm{O}_{2}}^{a}}{R T}\right)
$$

where $D_{\mathrm{O}_{2}}^{o}$ is the preexponential factor and $E_{\mathrm{O}_{2}}^{a}$ is the activation energy for the diffusion coefficient of oxygen in strong alkaline solution. ${ }^{10}$ The low value for the observed activation energy of $9.4 \mathrm{~kJ} / \mathrm{mol}$ is mainly related to the viscosity of the aqueous electrolyte and is in line with those generally reported for diffusioncontrolled processes. ${ }^{17}$ 
At higher temperatures, a clear deviation from the linear Arrhenius dependence is observed. It is suggested that this might be due to the fact that the wetting ability of the electrode is changing, resulting in a larger number of three-phase regions and, consequently, in a favorable combination of a larger wetted surface area $A_{\mathrm{Cd}}$ and smaller values for $d_{\mathrm{O}_{2}}$ (see Eq. 29). It should, however, be emphasized that this deviation toward higher values is in fact very attractive for the recombination reaction, keeping the internal gas pressure of the battery relatively low at higher temperatures.

It is desirable to keep the internal gas pressure inside rechargeable batteries as low as possible. From the present results, it becomes evident that this can be achieved by increasing the recombination rate. According to the lines of reasoning outlined above, this can be accomplished by increasing the number of three-phase boundary regions (see Fig. 10), i.e., by creating a larger number of both wetted and dry regions. By making use of specific additives creating both hydrophilic and hydrophobic regions, this would contribute to an enhanced recombination rate, keeping the internal gas pressure at more favorable levels.

Oxygen evolution.-The individual electrode potentials inside uncapped $\mathrm{NiCd}$ batteries have been studied by means of a reference electrode as a function of SOC in Fig. 4. Apart from the hysteresiseffect characteristic for the Ni electrode, the OCV behavior is in good agreement with what is expected on the basis of a normal solid-solution dependence, as represented by the Nernst equation. ${ }^{5,9}$ For example, the agreement of the theoretical curve (c) with the experimental curve (a) obtained during charging is very close, especially, up to $50 \%$ SOC. A value of $0.449 \mathrm{~V}$ for $E_{\mathrm{Ni}}^{o}$ has been used in the calculation of curve (c). A similar fit during discharging [curve (b)] reveals a value of $0.375 \mathrm{~V}$ for $E_{\mathrm{Ni}}^{o}$ during discharging. Similar values for the $\mathrm{Ni}$ hysteresis have been reported before. ${ }^{18-}$

More relevant for the present work is that curves (d) and (e) of Fig. 4 unequivocally show that the OCV of the $\mathrm{Cd}$ electrode is independent of its SOC. This also holds after relaxation from the overcharging region. Interestingly, this implies that the Cd electrode can be considered as an internal reference inside sealed NiCd batteries under the assumption that none of the current flowing through this electrode is used to drive the main electrochemical chargetransfer reaction (Eq. 2) and hence that the overpotential for the $\mathrm{Cd}$ reaction is zero. This result proves that the assumption of a constant $\mathrm{Cd}$ electrode potential in the derivation of the oxygen evolution kinetics (Eq. 21) is indeed fulfilled and that Tafel dependencies are to be expected.

Figure 7 shows, however, that a simple semilogarithmic Tafel behavior is not found. Two Tafel lines are found at all temperatures (Fig. 8). Such two-step processes have been reported before for the oxygen evolution reaction in alkaline solutions. ${ }^{21-23}$ According to Eq. 3, four electrons are involved in the overall reaction. Most likely, electron transfer will take place in successive steps, involving well known to be involved in most of the proposed oxygen evolution reaction mechanisms. ${ }^{21,24}$ In order to make the complexity of the mathematics not too high, only a sequential series of the four individual charge-transfer steps are considered in the present derivation. For a more detailed listing of the various possible oxygen evolution mechanisms, the reader is referred to Ref. 24-26. The following general reaction scheme can, in the simplest case, be considered

$$
\begin{aligned}
& S_{1} \rightleftarrows S_{2}+e^{-} \\
& S_{2} \rightleftarrows S_{3}+e^{-} \\
& S_{3} \rightleftarrows S_{4}+e^{-} \\
& S_{4} \rightleftarrows S_{5}+e^{-}
\end{aligned}
$$

with the overall reaction

$$
S_{1} \rightleftarrows S_{5}+4 e^{-}
$$

where $S_{1}=4 \mathrm{OH}^{-} ; S_{2}, S_{3}, S_{4}$ are the intermediate species $(S)$; and $S_{5}=\mathrm{O}_{2}(l)$. It is again assumed that the partial current-voltage dependencies for each charge-transfer step (Eq. 32-35) can be described by a Butler-Volmer-type of relationship, i.e.

$$
I_{j}=F A_{\mathrm{Ni}} k_{j}^{a} a_{S_{j}} \exp \left\{\frac{\alpha_{j} F}{R T} E_{\mathrm{O}_{2}}\right\}-F A_{\mathrm{Ni}_{i}} k_{j}^{c} a_{S_{j+1}} \exp \left\{\frac{-\left(1-\alpha_{j}\right) F}{R T} E_{\mathrm{O}_{2}}\right\}
$$

where $k_{j}^{a}$ and $k_{j}^{c}$ are the rate constants for the anodic and cathodic partial reaction, respectively, $a_{j}$ and $a_{j+1}$ are the activities of the $S_{j}$ and $S_{j+1}$ species, respectively, and $\alpha_{j}$ are the individual chargetransfer coefficients for each charge-transfer step $(j)$, where $j$ ranges from 1 to 4 . Evidently, since electron transfer takes place in individual steps, both $n$ and all reactions orders are now unity in all cases. It should, furthermore, be noted that it is essential to use the electrode voltage rather than overpotential (see Ref. 2 for detailed derivations) and that $E_{\mathrm{O}_{2}}=E_{\mathrm{Ni}}$. In addition, a steady-state situation is assumed for each reaction step, i.e., the concentrations of intermediate species $S_{2}, S_{3}$, and $S_{4}$ are considered constant. Under these conditions, the partial currents are equal

$$
I_{1}=I_{2}=I_{3}=I_{4}
$$

and the oxygen evolution current is the summation of the partial currents

$$
I_{\mathrm{O}_{2}}=I_{1}+I_{2}+I_{3}+I_{4}
$$

Eliminating the activities of the intermediate species from Eq. 37 by using Eq. 38 and 39, the following general expression for the oxygen current is obtained

$$
\begin{aligned}
I_{\mathrm{O}_{2}}= & 4\left[F^{4} A_{\mathrm{Ni}}^{4} k_{1}^{a} k_{2}^{a} k_{3}^{a} k_{4}^{a} a_{\mathrm{OH}^{-}} \exp \left\{\frac{\left(\alpha_{1}+\alpha_{2}+\alpha_{3}+\alpha_{4}\right) F}{R T} E_{\mathrm{O}_{2}}\right\}-F^{4} A_{\mathrm{Ni}}^{4} k_{1}^{c} k_{2}^{c} k_{3}^{c} k_{4}^{c} a_{\mathrm{O}_{2}} \exp \left\{-\frac{\left(4-\alpha_{1}-\alpha_{2}-\alpha_{3}-\alpha_{4}\right) F}{R T} E_{\mathrm{O}_{2}}\right\}\right] / \\
& {\left[F^{3} A_{\mathrm{Ni}}^{3} k_{2}^{a} k_{3}^{a} k_{4}^{a} \exp \left\{\frac{\left(\alpha_{2}+\alpha_{3}+\alpha_{4}\right) F}{R T} E_{\mathrm{O}_{2}}\right\}+F^{3} A_{\mathrm{Ni}}^{3} k_{1}^{c} k_{3}^{a} k_{4}^{a} \exp \left\{\frac{\left(-1+\alpha_{1}+\alpha_{3}+\alpha_{4}\right) F}{R T} E_{\mathrm{O}_{2}}\right\}\right.} \\
& \left.+F^{3} A_{\mathrm{Ni}}^{3} k_{1}^{c} k_{2}^{c} k_{4}^{a} \exp \left\{\frac{\left(-2+\alpha_{1}+\alpha_{2}+\alpha_{4}\right) F}{R T} E_{\mathrm{O}_{2}}\right\}+F^{3} A_{\mathrm{Ni}}^{3} k_{1}^{c} k_{2}^{c} k_{3}^{c} \exp \left\{\frac{\left(-3+\alpha_{1}+\alpha_{2}+\alpha_{3}\right) F}{R T} E_{\mathrm{O}_{2}}\right\}\right]
\end{aligned}
$$

single-electron transfer. The change from one Tafel slope to another suggests that the rate-determining step of the oxygen evolution reaction is changing as a function of the applied current. The mathematics for such a multistep oxygen evolution reaction will be derived below.

Apart from charge transfer, adsorbed intermediate species are
Similar expressions have been described in the literature before by for example, Vetter and Christiansen et al. ${ }^{23,27}$ However, contrary to the previous derivations, we have not assumed that each reaction step has the same equilibrium potential. Therefore, the current in Eq. 40 is expressed in terms of the oxygen potential rather than overpotential. 
Both the anodic and cathodic branch of the Butler-Volmer equation can be recognized at the two terms of the numerator in Eq. 40. The influence of the four sequential charge-transfer steps can be recognized at the various terms of the denominator. Depending on the values of the rate constants $k_{j}^{a}, k_{j}^{c}$, and $E_{\mathrm{O}_{2}}$, the denominator can be dominated by either one or more of the four exponential terms. This is the origin of the presence of one or more Tafel slopes in the standard $\log I_{\mathrm{O}_{2}}$ vs. $E_{\mathrm{O}_{2}}$ plot.

Considering that for single-electron transfer reactions $\alpha$ must be within 0 and 1 , it is obvious that

$$
\begin{aligned}
\left(\alpha_{2}+\alpha_{3}+\alpha_{4}\right) & >\left(-1+\alpha_{1}+\alpha_{3}+\alpha_{4}\right)>\left(-2+\alpha_{1}+\alpha_{2}+\alpha_{4}\right) \\
& >\left(-3+\alpha_{1}+\alpha_{2}+\alpha_{3}\right)
\end{aligned}
$$

For very high values of $E_{\mathrm{O}_{2}}$, it is clear that the first exponential term in the denominator of Eq. 40 will be dominant. Which exponent will be dominant for the lower values of $E_{\mathrm{O}_{2}}$ becomes apparent from the inspection of the Tafel plots. In our particular case, only two different Tafel slopes are observed. Interestingly, the slope for moderate values of $E_{\mathrm{O}_{2}}$ is of the order of $1 / 0.054 \mathrm{~V}^{-1}$ (in Fig. 7), indicating a unity $\alpha$ term in Eq. 41. This is only possible in one specific case: for moderate values of $E_{\mathrm{O}_{2}}$, the exponent corresponding to $\left(-1+\alpha_{1}+\alpha_{3}+\alpha_{4}\right)$ will be dominant. The remaining exponential factors corresponding to $\left(-2+\alpha_{1}+\alpha_{2}+\alpha_{4}\right)$ and $\left(-3+\alpha_{1}+\alpha_{2}+\alpha_{3}\right)$ can then be neglected. Assuming that the simplified reaction scheme of Eq. 32-35 applies, this would imply that in the first steep part of the semilogarithmic Tafel plots (see Fig. 7 and 8), the second charge-transfer step is rate-determining, while at higher currents the first charge-transfer step becomes ratedetermining

Together with the fact that the oxygen evolution occurs at relatively high overpotentials, the cathodic part in the numerator can again be neglected, resulting in a significantly simpler expression for the oxygen evolution current

$$
K_{2}=\frac{k_{1}^{c}}{4 F A_{\mathrm{Ni}_{1}} k_{1}^{a} k_{2}^{a} a_{\mathrm{OH}^{-}}} \exp \left\{-\frac{\left(1+\alpha_{2}\right) F}{R T} E_{\mathrm{Cd}}\right\}
$$

The results presented in Fig. 7 and 8 have been analyzed according to Eq. 44-46. The solid lines in these figures represent the fit results. It is clear that the agreement between the measurements (symbols) and the mathematical expression (lines) is excellent in all cases. From these fits, the most relevant parameters have been derived as a function of temperature.

In our earlier NiCd modeling work, ${ }^{10}$ we only adopted a onebranch oxygen evolution reaction. The present results show, however, that this assumption is far too simple. In order to cope with the more complex oxygen reaction sequence, we more recently modified these NiCd models by adopting the following equation

$$
I_{\mathrm{O}_{2}}=\frac{I_{l} I_{h}}{I_{l}+I_{h}}
$$

where $I_{l}$ and $I_{h}$ refer to low and high current region dependency, respectively. A similar equation is often adopted for mixed kinetic/ diffusion-controlled reactions. ${ }^{28}$ In the present case, Eq. 47 can be interpreted from the point of a kinetic/kinetic-controlled reaction, since at different voltages, different steps of a multistep reaction scheme are rate-determining. ${ }^{27}$ In the Appendix, it is shown that the general Eq. 44 can be easily transformed into expression 47 . From a practical point of view, Eq. 47 is, however, more convenient. Evidently, exactly the same simulation results are obtained in both cases (solid lines in Fig. 7 and 8).

Using this convenient form (Eq. 47) and assuming that the redox potentials for all electrochemical charge-transfer steps are the same, extrapolating the straight lines of Fig. 7 and 8 to the standard redox potential of the oxygen redox reaction yield values for $K_{\mathrm{O}_{2}}$ (see Eq 21). It should, however, be noted in this respect that both the values for $E_{\mathrm{O}_{2}}^{o}$ and $E_{\mathrm{Cd}}^{o}$ are temperature-dependent, according to Eq. 22. As adopted before, a value of +649 and $-204 \mathrm{~J} / \mathrm{mol} \cdot \mathrm{K}$ for $\Delta S_{\mathrm{O}_{2}}$ and $\Delta S_{\mathrm{Cd}}$, respectively, has been used for this temperature correction. ${ }^{10}$

$$
I_{\mathrm{O}_{2}}=\frac{4 F^{4} A_{\mathrm{Ni}}^{4} k_{1}^{a} k_{2}^{a} k_{3}^{a} k_{4}^{a} a_{\mathrm{OH}^{-}} \exp \left\{\frac{\left(\alpha_{1}+\alpha_{2}+\alpha_{3}+\alpha_{4}\right) F}{R T} E_{\mathrm{O}_{2}}\right\}}{F^{3} A_{\mathrm{Ni}}^{3} k_{2}^{a} k_{3}^{a} k_{4}^{a} \exp \left\{\frac{\left(\alpha_{2}+\alpha_{3}+\alpha_{4}\right) F}{R T} E_{\mathrm{O}_{2}}\right\}+F^{3} A_{\mathrm{Ni}}^{3} k_{1}^{c} k_{3}^{a} k_{4}^{a} \exp \left\{\frac{\left(-1+\alpha_{1}+\alpha_{3}+\alpha_{4}\right) F}{R T} E_{\mathrm{O}_{2}}\right\}}
$$

or

$$
I_{\mathrm{O}_{2}}=\frac{4 a_{\mathrm{OH}^{-}}}{\frac{1}{F A_{\mathrm{Ni}} k_{1}^{a}} \exp \left\{-\frac{\alpha_{1} F}{R T} E_{\mathrm{O}_{2}}\right\}+\frac{k_{1}^{c}}{F A_{\mathrm{Ni}} k_{1}^{a} k_{2}^{a}} \exp \left\{-\frac{\left(1+\alpha_{2}\right) F}{R T} E_{\mathrm{O}_{2}}\right\}}
$$

Since $E_{\mathrm{O}_{2}}=E_{\mathrm{Ni}}=E_{\mathrm{NiCd}}+E_{\mathrm{Cd}}$ and $E_{\mathrm{Cd}}$ has been proven to be constant under steady-state conditions, we finally obtain

$$
I_{\mathrm{O}_{2}}=\frac{1}{K_{1} \exp \left\{-\frac{\alpha_{1} F}{R T} E_{\mathrm{NiCd}}\right\}+K_{2} \exp \left\{-\frac{\left(1+\alpha_{2}\right) F}{R T} E_{\mathrm{NiCd}}\right\}}
$$

in which

$$
K_{1}=\frac{1}{4 F A_{\mathrm{Ni}_{1}} k_{1}^{a} a_{\mathrm{OH}^{-}}} \exp \left\{-\frac{\alpha_{1} F}{R T} E_{\mathrm{Cd}}\right\}
$$

and
Figure 12 shows the as-obtained values for $K_{\mathrm{O}_{2}}$ as a function of the reciprocal temperature. Although the scatter is substantial, straight lines can be derived for both the low and high current regions. From the slope of the low-current dependence [curve (a)], an activation energy of $66.2 \mathrm{~kJ} / \mathrm{mol}$ is calculated. Surprisingly, the high-current results do not reveal any temperature dependency [curve (b)]. Such temperature-independent behavior has been reported before for the hydrogen evolution reaction. ${ }^{21}$

The values for $\alpha$ can be calculated from the slope of the Tafel lines in Fig. 7 and 8. Both the low-current alpha $\left(\alpha_{l}\right)$ and highcurrent alpha $\left(\alpha_{h}\right)$ clearly reveal the same temperature dependence in Fig. 13, with $\alpha_{l}$ significantly higher than $\alpha_{h}$. Conway reported and discussed the temperature dependence of alpha extensively and attributed this to the temperature-dependent free-energy curves. ${ }^{21}$

So far, only the steady-state results have been discussed. Figure 2 revealed that after raising the overcharging current, the battery voltage instantaneously increases and, subsequently, slowly decreases in time toward a new steady-state value. On the other hand, the pressure rises slowly and the new steady-state pressure is reached after the same voltage relaxation time. In order to explain this behavior, we must discuss Fig. 10 in somewhat more detail.

Referring to steady-state currents, $I_{1}$, in Fig. 10 it is clear that the rates of oxygen evolution and oxygen recombination are exactly 


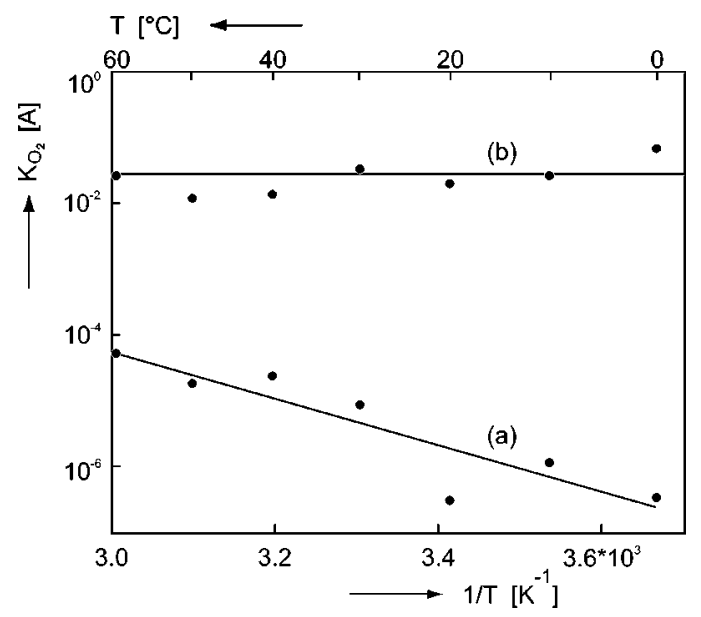

Figure 12. $\mathrm{K}_{\mathrm{O}_{2}}$, as obtained from extrapolating the low [curve (a)] and high current [curve (b)] Tafel lines (Eq. 21) shown in Fig. 7 and 8 to $E_{\mathrm{O}_{2}}^{\text {eq }}$, as a function of the reciprocal temperature.

balanced, as is schematically indicated in the current-voltage curves (a) and (c). Here it is important to note that the diffusion-controlled oxygen recombination current is, according to Eq. 29, proportional to the partial oxygen pressure inside the battery and that the evolution and recombination reaction take place at $E_{\mathrm{Ni}}^{\mathrm{eq}}$ and $E_{\mathrm{Cd}}^{\mathrm{eq}}$, respectively. An instantaneous change of the current to a higher level by an amount $I_{2}$ (i.e., $I_{\text {applied }}=I_{1}+I_{2}$, see Fig. 2) cannot induce an immediate pressure increase as the oxygen recombination rate remains at the same level $I_{1}$ (see Fig. 10). Consequently, the increased current $\left(I_{2}\right)$ must at least partly flow toward the main electrochemical storage reaction of the $\mathrm{Cd}$ electrode under the condition that $I_{\text {applied }}$ $=I_{1}+I_{2}=I_{3}$. This results in the instantaneous, but temporary, change of the $\mathrm{Cd}$ electrode potential toward more negative voltages (see the $I_{2}$ voltage position in Fig. 10) and a small increase of SOC of the $\mathrm{Cd}$ electrode. As the oxygen evolution rate at the $\mathrm{Ni}$ electrode is at a higher level, it is evident that the partial oxygen pressure will slowly rise as the experiments in Fig. 2 indeed indicate. As a result, the recombination current plateau starts to increase and the Cd reaction rate will simultaneously diminish slowly to zero. Since the $\mathrm{Cd}$ electrode potential is independent of SOC (Fig. 4), the new steady-state situation is reached when the oxygen pressure is adjusted at that level where $I_{\mathrm{O}_{2}}$ equals $I_{\text {rec }}$ again $\left(=I_{3}\right.$ in Fig. 10). Under that condition, the $\mathrm{Cd}$ electrode potential has returned to the same

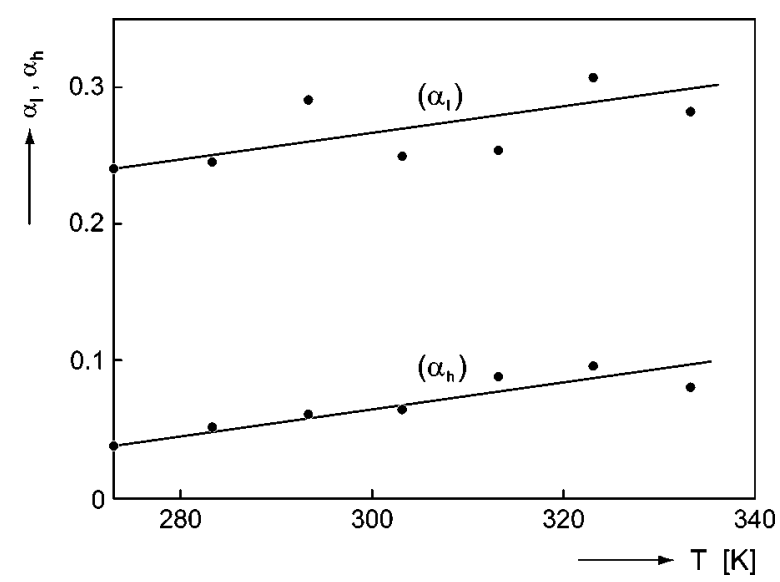

Figure 13. $\alpha_{l}$ and $\alpha_{h}$, as obtained from the respective slopes of the lowcurrent and high-current Tafel lines (Eq. 21) shown in Fig. 7 and 8, as a function of temperature. steady-state voltage as before $\left(E_{\mathrm{Cd}}^{\mathrm{eq}}\right)$ and $I_{2}$ has become zero. The situation for the Ni electrode is somewhat different as $E_{\mathrm{Ni}}^{\mathrm{eq}}$ is dependent on SOC (Fig. 4), especially at higher levels of SOC. Here, a new steady-state situation is reached $\left[I_{3}\right.$ in curve (c) of Fig. 10], where the current-potential curves of the Ni electrode and, consequently, the OCV are shifted toward more positive values [compare dashed lines of curves (d)]. A reversal of a voltage shift is, in contrast to the $\mathrm{Cd}$ case, not to be expected for the Ni electrode, and hence the battery voltage reduction upon current increase as observed in Fig. 2 must be attributed to the specific $\mathrm{Cd}$ electrode characteristics.

In previous work, we have described our modeling activities for aqueous battery systems, including $\mathrm{NiCd}$ and $\mathrm{NiMH},{ }^{5,9-12}$ and organic Li-ion systems. ${ }^{5,29}$ The present results show that the oxygen recombination cycle inside $\mathrm{NiCd}$ is rather complex. It is very likely that the results can also be applied to other Ni-based battery systems, which are based on a similar oxygen recombination mechanism. A requirement is, of course, that the kinetics of both oxygen evolution and recombination reactions does not differ substantially. Since it is well known that the kinetics of electrochemical reactions strongly depends on the concentrations of the electroactive species involved, it is evident that in order to apply the present kinetic parameter values, the (electro)chemical conditions may not differ too much. Since the NiMH battery system is based on a similar oxygen recombination cycle, ${ }^{2}$ includes a similar type of $\mathrm{Ni}$ electrode, and also operates in a similar strong alkaline electrolyte, it seems reasonable to assume that the kinetics derived in the present paper can also be adopted for this battery system. It should, however, be emphasized that minor changes in the chemical composition between NiCd and NiMH batteries might be important and might induce kinetic and even mechanistic changes. It is worthwhile to note that the complexity inside NiMH is much higher as hydrogen will certainly contribute to the total gas pressure inside NiMH batteries. It has recently been experimentally confirmed by in situ Raman spectroscopic measurements. ${ }^{30,31}$ These more detailed measurements carried out with NiMH batteries will be reported separately in the near future.

\section{Conclusions}

The kinetics of the electrochemical oxygen evolution and oxygen recombination reaction has been investigated under thermostated, steady-state conditions at $\mathrm{NiCd}$ batteries within a temperature range of $0-60^{\circ} \mathrm{C}$. The electrode potential of the Cd electrode was shown to be constant under these steady-state overcharging conditions, allowing us in situ to quantify the oxygen evolution kinetics at the $\mathrm{Ni}$ electrode. The oxygen evolution reaction was clearly found to be a two-step process. Each step was characterized by a specific Tafel slope and revealed that the rate-determining step is changing from low-current overcharging to high-current overcharging. A transfer from one rate-determining step to another takes place in the intermediate region. The intermediate kinetics could be perfectly described by a serial reaction sequence.

Oxygen recombination kinetics was found to be first-order in oxygen pressure, most likely diffusion-controlled by oxygen redissolution from the gas phase into the electrolyte, preferably in the solid/electrolyte/gas, three-phase boundary layers near the $\mathrm{Cd}$ electrode. Recombination is enhanced at higher temperatures, resulting in significantly reduced pressures. Due to the extremely high overpotential at which the oxygen reduction at the $\mathrm{Cd}$ electrode occurs, it is most likely that the reaction is controlled by transport of oxygen through the electrolyte. Apparent diffusion rate constants have been derived, which were found to be dependent on the ambient temperature. 
In our previous $\mathrm{NiCd}$ models, the oxygen recombination cycle was modeled in a rather simple way. The oxygen evolution reaction was considered as a one-step electrochemical reaction and the recombination kinetics was considered to be diffusion-controlled. ${ }^{10,12}$ The present results show that the rate laws for the oxygen evolution kinetics are much more complex and have to be modified. In Ref. 5, the kinetics of the two-step reaction has indeed recently been introduced in the current models.

Since the overcharging chemistry of NiMH batteries is very similar to that of NiCd batteries, the present results can most likely also be adopted for advanced NiMH models. NiMH modeling is currently in progress. ${ }^{11}$

\section{Acknowledgments}

The authors thank A.A. Janssen van Rosendaal for his experimental support. They are also grateful to Matsushita Battery Industries for supplying the 80AAS batteries. Dr. Nakao and Mr. Ugaji (Matsushita Electronic Industries) and Ing. van Beek (Philips Research Laboratories) are acknowledged for many helpful and stimulating discussions.

Philips Research Laboratories assisted in meeting the publication costs of this article.

\section{Appendix}

Equation 44 can be rewritten in a more convenient form, using the following simple equality

$$
\frac{1}{x+y}=\frac{\frac{1}{x y}}{\frac{1}{x}+\frac{1}{y}}
$$

Equation A-1 can then be rewritten as

$$
I_{\mathrm{O}_{2}}=\frac{I_{l} I_{h}}{I_{l}+I_{h}}
$$

where

$$
\begin{gathered}
I_{l}=\frac{4}{K_{2}} \exp \left\{-\frac{\left(1+\alpha_{2}\right) F}{R T} E_{\mathrm{NiCd}}\right\} \\
I_{h}=\frac{4}{K_{1}} \exp \left\{-\frac{\alpha_{1} F}{R T} E_{\mathrm{NiCd}}\right\}
\end{gathered}
$$

\section{References}

1. Handbook of Batteries, 2nd ed., D. Linden, Editor, McGraw-Hill, New York (1995).

2. P. H. L. Notten, in Interstitial Intermetallic Alloys, F. Grandjean, J. T. Long, and K. H. J. Buschow, Editors, Vol. 281, Chap. 7, p. 151, NATO ASI Series E: Applied Science, Kluwer Academic, London (1995).

3. P. H. L. Notten and J. R. G. van Beek, Chem. Ind., 54, 102 (2000).

4. K. Mizushima, P. C. Jones, P. J. Wiseman, and J. B. Goodenough, Mater. Res. Bull., 15, 783 (1980).

5. H. J. Bergveld, W. S. Kruijt, and P. H. L. Notten, Battery Management Systems: Design by Modelling, Kluwer Academic, Boston (2002).

6. J. S. Newman, Electrochemical Systems, 2nd ed., Chap 11, Prentice Hall Inc., Englewood Cliffs, NJ (1991).

7. J. W. Weidner and P. Timmerman, J. Electrochem. Soc., 141, 346 (1994).

8. D. Fan and R. E. White, J. Electrochem. Soc., 138, 2952 (1991).

9. W. S. Kruijt, H. J. Bergveld, and P. H. L. Notten, J. Electrochem. Soc., 145, 3764 (1998).

10. P. H. L. Notten, W. S. Kruijt, and H. J. Bergveld, J. Electrochem. Soc., 145, 3774 (1998).

11. A. Ledovskikh, E. Verbitski, A. Ayeb, and P. H. L. Notten, J. Alloys Compd., 356-357, 742 (2002).

12. H. J. Bergveld, W. S. Kruijt, and P. H. L. Notten, J. Power Sources, 77, 143 (1999).

13. R. Barnard, J. Appl. Electrochem., 11, 217 (1981).

14. S. U. Falk and A. J. Salkind, Alkaline Storage Batteries, John Wiley \& Sons, New York (1969).

15. T. Nakao and M. Ugaji, Private communication.

16. R. E. Davis, G. L. Horvath, and C. W. Tobias, Electrochim. Acta, 12, 287 (1967).

17. P. H. L. Notten, J. E. A. M. van den Meerakker, and J. J. Kelly, Etching of III-V Semiconductors: An Electrochemical Approach, Elsevier Science Publishers, Oxford (1991).

18. D. M. MacArthur, J. Electrochem. Soc., 117, 422 (1970)

19. K. P. Ta and J. Newman, J. Electrochem. Soc., 146, 2769 (1999).

20. V. Srinivasan, J. Weidner, and J. Newman, J. Electrochem. Soc., 148, A969 (2001).

21. B. E. Conway, in Modern Aspects of Electrochemistry, B. E. Conway, R. E. White, and J. O'M Bockris, Editors, Vol. 16, Chap. 2, p. 103, Plenum, New York (1985).

22. P. Delahey, Double Layer and Electrode Kinetics, Interscience Publishers, John Wiley \& Sons, New York (1966).

23. K. J. Vetter, Electrochemical Kinetics, Academic Press, New York (1967).

24. J. O'M. Bockris, J. Chem. Phys., 24, 817 (1956).

25. A. T. Erdey-Grüz, Kinetics in Electrode Processes, Chap. 4, Adam Hilger Ltd., London (1972).

26. J. McBreen, Modern Aspects of Electrochemistry, 21, 29 (1990).

27. J. A. Christiansen, Z. Phys. Chem. Abt. B, 33, 145 (1936).

28. A. J. Bard, Electrochemical Methods: Fundamentals and Applications, John Wiley $\&$ Sons, New York (2001)

29. P. E. de Jongh and P. H. L. Notten, Solid State Ionics, 148, 259 (2002)

30. A. Belfadhel-Ayeb and P. H. L. Notten, 55th Annual ISE Meeting, Thessaloniki, Greece (2004).

31. A. J. G. Mank, A. Belfadhel-Ayeb, P. V. E. Krüsemann, and P. H. L. Notten, Appl. Spectrosc., 59, 109 (2005). 